\title{
A Review of Effective Doctoral Supervision: What Is It and How Can We Achieve It?
}

\author{
Alias Masek*, Maizam Alias \\ Faculty of Technical and Vocational Education, Universiti Tun Hussein Onn Malaysia, 86400 Batu Pahat, Johor, Malaysia
}

Received March 18, 2020; Revised April 23, 2020; Accepted May 3, 2020

Copyright $\subseteq 2020$ by authors, all rights reserved. Authors agree that this article remains permanently open access under the terms of the Creative Commons Attribution License 4.0 International License

\begin{abstract}
The success of doctoral students greatly depends on effective supervision. Many factors however, are involved in ensuring effective supervision. This study identifies the different definitions of effective supervisions, types of doctoral outcomes and the associated factors that contribute to these outcomes, with a view of proposing a framework to achieve the goal of effective supervision. A systematic review was conducted on published articles from the year 2000 to the year 2018 . The documents were selected based on the three major components of doctoral supervision namely, management system, students and supervisor, thus framing the systematic review. The review resulted in several key findings namely, definitions, domains of doctoral outcomes and factors that can potentially contribute to doctoral outcomes. Diverse definitions of effective supervision were observed; often associated with self-development, professional growth and career development of doctoral students. Four domains of doctoral outcomes were identified: knowledge-base, research skills, attitudes and professional skills. Factors that influence doctoral outcomes include environment, attitude and aptitude of doctoral students, and experience and training of supervisors. The findings of this review provide useful information for guiding the implementation of an effective supervision framework.
\end{abstract}

Keywords Doctoral Studies, Effective Supervision, Research Supervision, Postgraduate Supervision, Supervision Theory, Systematic Review

\section{Introduction}

Innovations and new knowledge would not be possible without the contributions from researchers around the globe. Thus, developed nations are more advanced in virtually every field of knowledge compared with those, which are developing because the former has a higher number of research personnel. Take the example of Malaysia and Japan: Malaysia as a developing nation has 1,643 researchers per million people whilst Japan as a developed nation has 5,158 researchers per million people [1]. These data include doctoral students as part of the research personnel statistics.

Although graduate research students are contributing to the research personnel statistics, having them graduated on time would be more beneficial as supervisors whose students have graduated will be available to train new research students - leading to more research personnel. Supervisors who manage to graduate research students on time are those who can provide good and effective supervision. Effective supervision however, seems to be elusive to some due to several factors. For a start, there is no agreed definition of effective supervision; it varies according to institutions depending on an institution's vision and mission, and values [2], and research output, as well as educational policies [3] where a university is often made responsible in fulfilling the interest of stakeholders. Such circumstances have resulted in varying definitions of effective supervision in the current literature.

A greater emphasis on impact and research output to be achieved at a reduced research cost has led to changes in the nature of doctoral supervision across field. Doctoral students are sometimes retained for a longer period than necessary in their learning institutions, as they are often major contributors in research output and publications. Though beneficial to some extent, extended study duration can be detrimental to both candidates and institutions. Delayed completion of study can lead to non-completion and when that happens, it can be stressful for the candidate. Also, it is a loss of valuable time and resources for the institutions such as universities that are involved in the training of the candidate. Thus, on-time graduation of doctoral candidates is more beneficial to both; the candidates are accorded recognition upon their completion and the university gains a better reputation as 
the number of doctoral students graduating on time contributes to a better ranking of the university. Thus, graduating on time has been accepted as an important goal for higher learning institutions that offer doctoral programmes [3,4].

To ensure students graduate on time, various measures are being undertaken by institutions such as recruiting highly capable candidates, implementing effective thesis supervision and establishing efficient management of doctoral programmes. Among the three measures, the second, i.e. effective supervision has been identified as the key to achieve on-time graduation of candidates enrolled in a doctoral programme [3,5]. In fact, providing effective research supervision is crucial irrespective of students' capability as suggested by Gill and Burnard [6]. According to Gill and Burnard [6] , while ineffective supervision involving highly capable doctoral candidates may simply lead to longer study duration, ineffective supervision of less capable candidates may lead to non-completion of the research. Either way, the outcome is not beneficial to both.

Existing literature suggests that an effective supervision is influenced by three major components in higher education namely; management system, students and supervisors. From a system perspective, the definition of effective supervision varies according to discipline, area, and programmes [2]. Furthermore, universities have policies, rule and regulation for postgraduate studies that differ from one university to another. Thus, in addition to the definition specifics of the discipline and area of study, dissimilar mission and value propositions possessed by different universities are also contributing to the variations in the definition of effective supervision. Grant, Hackney and Edgar [2] have attempted to generalize the definition of effective supervision based on policies from several international universities by proposing a policy for supervisor roles (do's and don'ts). However, the policy does not differentiate between good or poor students and also does not mention the importance of relationship and it has been seen as a protective mechanism from students' complaining. Definition on effective supervision is also affected by the failure of several system predictors in determining students' completion in doctoral studies, including the weakness of doctoral programme, availability of funding, and access to laboratory equipment [7].

From the students and supervisor point of view, Jones [8] has highlighted that an effective supervision is an issue of the quality of supervisor, attrition, social isolation, and relationships between both parties. Students often perceive that a friendly supervisor, providing consultation and feedback, constitutes an effective supervisor [9]. Quality of supervisor has become the prominent factor that includes various personal characteristics (i.e., approachable, supportive, positive, open mindedness), knowledge, experiences, and expertise. For an effective supervision to occur, student should also come with a particular quality in terms of attitudes, experience in learning and good interpersonal skills. Azure [9] highlighted the importance of students' personal characteristics such as gender, socio-economic, and employment status in establishing effective supervision. When both parties achieve the stated quality, a good relationship can be established, which is the key to effective supervision [8,10,11]. In addition to good relationship that may affect supervision, both supervisor and student also have their own expectations on the supervision process [11]. These expectations are associated with all the contexts of quality mentioned above, including supervisors and students' characteristics. Thus, the importance of supervisor and students' characteristic is influencing effective supervision that has been supported by many $[2,8,12]$. A supervision triangle as shown in figure 1 is proposed based on the three major components of supervisions discussed in the above.

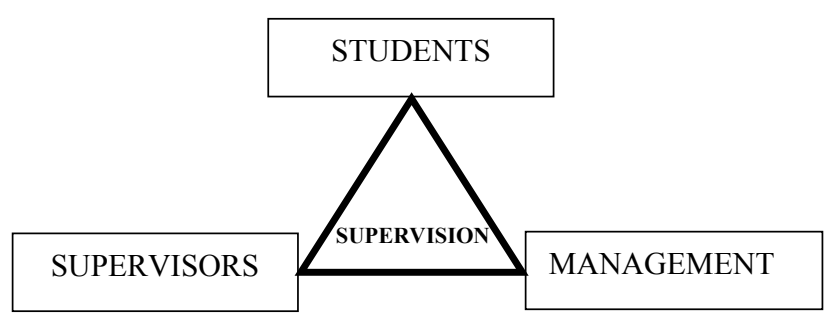

Figure 1. Supervision triangle: Interactive factors in a doctoral supervision process

Thus, the meaning of effective supervision may vary according to the interaction among the management system, students and supervisors.

\subsection{Problem Statement}

Although effective supervision has been identified as a key factor in ensuring on-time graduation of research students, the definition of effective supervision is yet to be agreed upon as the definition is influenced by several interacting factors that contribute to on-time graduation namely, students' characteristics, supervisors' characteristics and the existing management system. A good definition of effective supervision is essential as it can help in the development of tools for assessing supervision quality. Furthermore, a clear understanding of effective supervision and factors that contribute to it can greatly assist in establishing a working framework for achieving on-time graduation via effective supervision. The framework would provide supervisors with a big idea on how to navigate their student-supervisor journey in the research process. While the characteristics of the management system are important, their effect on graduation time is not as critical since they are less dynamic compared to students' and supervisors' characteristics.

If the management system is to be removed from 
considerations, the student-supervisor relationships would become the key factor in influencing graduation time. Thus, the aim of this systematic review is to understand the elements that constitute effective supervision, types of doctoral outcomes and the associated student and supervisor characteristics that contribute to these outcomes, with a view of proposing a framework to achieve the goal of on-time graduation via effective supervision. As the supervisor-students' relationship is now the focus of the literature review and since we are more interested in supervisor-students' relationship, the management system component was excluded in shaping our in-depth analysis of the selected literature. The following questions were posed to guide our work:

i. What are the definitions of effective doctoral supervision?

ii. What are the types of doctoral outcomes?

iii. What are the factors that contribute to effective supervision?

\subsection{Concepts of Doctoral Supervision}

Thesis supervision is an essential element in a doctoral study. Supervision can be provided by a single thesis supervisor, a group of supervisors where one takes the role of a main supervisor while the rest serves as the co-supervisors or a supervision committee consisting of faculty members who each plays a specific role assigned to them. A single supervisor and groups of main and co-supervisors are often practiced in countries such as the United Kingdom [11], while the supervisory committee is practiced in countries such as the United States of America [13].

A doctoral supervisor is an important individual who acts in multiple roles to ensure that doctoral students are able to complete their research within the stipulated time frame. The supervisor can be acting as a manager, director, friend, supporter, advisor, examiner, teacher, and facilitator [14]. In a single supervisor case, it is more crucial for the concerned supervisor to have a wide repertoire of knowledge and skills to effectively serve in their various roles, in contrast to the grouped and committee supervision where different roles can be assigned among the contributing supervisors. In the single supervision case, establishing an effective supervisor-student relationship is key to doctoral success $[6,7,8,10,11]$ as the student can only rely on one supervisor to provide guidance. Failure to form a good working relationship can lead to failure in thesis completion $[6,7,8,10,11]$ Establishing effective student-supervisor relationship is also important in the grouped supervision case where one supervisor (main supervisor) is in a dominant role while co-supervisors only play minimal role. Thus, this review was more into the supervisory system where either one supervisor plays a dominant role (single supervision or co-supervision) and less focused on committee-based supervision.
Students can nominate their potential supervisors or leave the choice to the learning institutions which uses the field of expertise as the criterion for selection of supervisor. Students' nomination on the other hand would often include expertise as well as perceived compatibility as the criteria. Students may also be assigned with co-supervisors depending on requests from them or universities' regulations.

Once enrolled as a doctoral student, a supervisor is often the first person that they have consultation with. At this meeting, proposed research work and direction, academic matter, future meeting schedule would be decided and ideally, based on the mutual agreement between student and supervisor. Supervisor then guides student throughout the doctoral process as stipulated by the university's academic regulations. These processes would include millstones such as passing the proposal defence, attending a mock viva session and passing the final viva voce examination. Thus, a supervisor plays a key role in determining a student's success in their doctoral studies. Along the way, supervisors have to give supervisory input on research goals and tasks while striving to establish a good working student-supervisor relationship $[6,7,8,10,11]$. Integral to the supervision role is managing the doctoral process which includes managing matters (i.e. management system) related to study duration, assessments and examination (stages and format), graduation requirements (such as publications frequencies), students' support system including attendance in short courses and seminars. In short, while striving to graduate on time, students need to manage the process as well as the supervisor. Understanding the concepts of doctoral supervisor and supervision can help both the supervisors and students navigating the doctoral journey.

\section{Methodology}

A systematic literature review was conducted on articles published between the year 2000 to 2018 that contain several combinations of keywords "doctoral supervision in education". The document search was conducted primarily using Google Scholar search engines. The returned documents were very large in number and a quick review of the abstracts indicates that the documents can be categorised into the three major components of doctoral supervision namely, management system, students and supervisor, which was used to frame the systematic review.

Articles were further screened and selected based on the following five criteria; the articles i) contain the word, 'system', 'supervisor characteristic', and 'students' characteristics' within the discussion section ii) are available in full text, iii) are research papers, iv) are relevant to "effective supervision" themes, and v) in the context of educational research. The selected articles were then downloaded and indexed, and the information was 
recorded into a matrix form for easy reference.

Finally, a total of 34 papers were scrutinized. The focus is on defining effective supervision in the context of supervisor-students relationship. The rest of the papers were put aside for future references.

\section{Result and Discussion}

Ineffective supervision is often the result of several interacting factors such as, different expectations, contrasting ways of thinking and working, and clashes of personality [11,12]. Therefore, it is envisaged that appropriate expectations, thinking and personality will contribute significantly to effective supervision.

Problems identified as contributors to non-completion of doctoral studies include inadequate supervision; emotional and psychological issues; lack of understanding and communication between supervisors and research students; and students' lack of knowledge, skills, training or experience in research methods [15]. These factors indicate that some elements are static and individually based (such as inadequate supervision or poor research skills) while others are dynamic, i.e. influenced by the quality of interactions between students and supervisors (such as lack of understanding). However, it must be appreciated that supervisors and students do not exist in a vacuum; they exist in an environment which could be conducive or detrimental to research endeavours. Thus, it is important to identify the characteristics that each player (student and supervisor) brings to supervision, possible dynamics of interactions between these players, and the adequacy of support provided by the environment to foster a better understanding of effective supervision.

If the supervision environment is at the ideal state, there remains two key elements that influence the supervision process success, namely, students and supervisors. The student-supervisor relationship or fit between the two will be the key factor in the success of the supervision process, as long as both parties have a mutual understanding of their expectations. Research indicates three major areas that are necessary for establishing effective supervision namely, fit in expectation $[2,6,8,12,15,16,24]$, fit in thinking $[15,16,17,24,26,27]$, and fit in personality and styles $[2,6,12,16,18,19,20,21,22,23]$. The different types of fits are going to be discussed next.

\section{(i) Fit in expectations}

According to Gill and Burnard [6], failure to discuss expectations among supervisors and research students may be a key factor that leads to supervisory problems. Research students expect their supervisors to be innovative, creative problem solvers, resource-oriented, work-focused, technical experts, decisive and dependable, and comfortable to work with [15]. Thus, supervisors should be helpful and supportive, and respect ideas that are generated by students in their professional field. On the other hand, supervisors expect their research students to be competent, reliable and self-directed. They need research students who have the ability to solve research problems and draw meaningful conclusions. Furthermore, supervisors expect their research students to possess good ethics in citing works of other researchers and be able to understand the process of research work. These expectations must be discussed and agreed upon at the initial stage of the supervision.

Mismatches of expectations often occur between students and their supervisors because the former has preconceived ideas about learning and the research culture they are entering; a universal problem happened to both international and home-based students. Either party could cause difficulties in the student-supervisor relationships and in the development and success of research projects. Grant, Hackney and Edgar [2] highlighted that successful supervision was not merely dependant on scholarly activities. Building an effective professional relationship with the students was one of the most important aspects. Potential difficulties sometimes do not manifest themselves in the early stage of doctoral studies but only arise as students move into later stages of their postgraduate studies. Difficulties arise as further learning leads to more complex conceptualisation; complications crop up as research questions become clearer and debate begins to require interpretations, drawing of findings and conceptual conclusions $[8,24]$. Therefore, the differences in expectations between supervisors and research students may lead to the failure of the research supervision process.

\section{(ii) Fit in thinking}

Effective supervision can have different meanings depending on the person' role: supervisor or doctoral candidate [25], and whether the individual concerned is looking at the outcomes or the process aspects of supervision [15]. For example, from the doctoral student's perspective, effective supervision is a factor that leads to self-development, professional growth and career development [26]. Thus, in this context, effective supervision would be conceptualised through indicators such as frequency of consultations (process aspect) and on-time graduation (outcome aspect). From the supervisor's perspective, effective supervision can be defined using similar indicators but of different quality. For example, effective supervision from students' perspective is when students can see their supervisors anytime they wish, while for a supervisor it can be based on scheduled intervals. In short, effective supervision is contextually based and thus needs to be understood from both the perspectives of students and supervisors; the perceived meaning of effective supervision can influence expectations and subsequent actions of both parties.

In addition to meanings, any efforts to understand the 
effective supervision construct and recommendation of effective supervision strategies need to be based on the outcomes that each party expects from the doctoral studies. Different outcomes may emphasise different aspects of the supervision process. The success or failure of doctoral supervision is judged by the outcomes achieved at the completion of the doctoral studies. The value a supervisor places on each type of outcome will certainly influence his or her expectations of the doctoral candidates. Shaw and Green [27] suggest four types of outcomes of doctoral studies, namely knowledge-based outcomes, research skills, attitudes and professional skills.

For the knowledge-based outcomes, doctoral students are expected to create and interpret new knowledge to satisfy peer review, extend the discipline and merit publication [28]. Thus, with the knowledge-based expectations, the quality of supervision and mentoring will be duly tuned through collaborations, networking, and research environment; these emphases will make a difference in the experiences and productivity of the early careers of postdoctoral researchers.

On the other hand, if the expectation is on development of research skills, i.e. development of general ability to conceptualise, design and implement a project, students will need support to cultivate their abilities to communicate ideas and conclusions clearly and effectively to expert and non-expert audiences. Thus, throughout the doctoral years, supervisors may look for opportunities for students to express and explore the passions of their research. If the supervisors focus on this outcome, doctoral students will have the opportunity to determine how this passion can contribute to their motivation for a career in academia [12].

If students are expected to undertake research and development at an advanced level, the supervision will focus on facilitating a positive environment for the development of new techniques, ideas, or approaches [25]. Students under such supervision will develop highly positive attitudes of learning in the process. Measures of students' engagement are valuable because they are considered reliable measures of learning processes, learning outcomes and enhancements aimed at improving the quality of learning experiences [29].

Lastly, if acquisitions of professional skills are the expected outcomes of the doctoral studies, development of attitudes, interpersonal skills, technical skills, and networking will be emphasised. Supervisors who want to see professional skills development in their students will try to provide opportunities for them to develop social and technical skills to deal with emotional and cognitive aspects of the doctoral research [30]. In summary, understanding what effective supervision means cannot be separated from expectations and outcomes.

Focusing on university research endeavours, Bøgelund [31] identified three types of emphasis where research is concerned: high quality research, economically viable and efficient research, and internationally adapted research.
Choice of emphasis will influence the way supervisors supervise their students. To put it another way, the views held by supervisors on the target of university research will influence the way they supervise doctoral students. In short, the doctoral outcomes expected by supervisors will influence the quality of their supervision with respect to the content of the supervision process. However, the effectiveness of supervisions is subject to the supervisors' ability to integrate the content of the supervision process with the students' willingness to work together. Thus, the key to effective supervision lies in the initial communication between supervisors and students to thrash out expectations and come to terms with mutually agreeable outcomes which will ensure continuing good relationship until completion of projects [32].

\section{(iii) Fit in personality and styles}

Regarding fit in personality and styles, researchers have greatly discussed the effect of personality and styles on effective supervision in the literature. For example, Mainhard et al., [21] suggest that a mismatch in personality between supervising style and learning style can greatly influence the effectiveness of supervision. Personality difference can create poor perceptions of each other, and if accompanied by poor communications, it can lead to loss of motivation on the student's side. Different characteristics of supervisors and research students such as age and gender can sometimes create such communication barrier between them that prevents development of effective supervision [9,16,23].

Previous studies also indicate that poor interpersonal working relationships between supervisors and research students can contribute to non-satisfaction and slower progress in research work $[9,33,34]$. The work relationship between supervisors and research students involves many key activities; planning of research, carrying out literature review, issues in research, selecting a topic of research, managing research, accessible resources, publication writing for conferences or journals, interpretation of data and writing reports as well as defending the proposals and viva. A good relationship is dependent on characteristics of supervisors and research students, disciplinary differences and different learning tasks $[10,12,22,35]$.

\section{(iv) Summary: Factors that contribute to effective supervision}

As supervisors are under pressure to help researchers graduate and begin their career as early as possible, it is important that they have the knowledge and understanding of the factors associated with students' retention and completion. Thus, the factors identified in the present study make several noteworthy contributions to having a good interpersonal working relationship between supervisors and research students.

Based on the literature, it can be summarised that 
effective supervisions are highly influenced by the relational fit between supervisors and students in the form of thinking fit, expectation fit and personality fit. Fit in personality can be established by ensuring students and supervisors have opportunities to get to know one another prior to an official appointment. Additionally, the competences (i.e. knowledge, skill, attitudes) of supervisors and students can also influence establishing of effective supervision, while the environment may also contribute indirectly to effective supervision. Meanwhile, both supervisor and students have own perception and styles; both must have a clear goal and understand the process to develop a mutual expectation for a good working relationship. Since fit seems to be the key to effective supervisions, establishing fit is important.

\section{(v)Recommendation}

A framework is proposed which seeks to address the overriding factors hindering effective doctoral supervision that are identified from the literature. The major part of the review points to students' failure to develop mutual relationships and communicate ideas of research clearly during completion time. Failure to establish good working relationship and ineffective communication of research intents of which, often rooted in unmet expectations have contributed towards high attrition rate. In other words, attrition problem can be the consequence unmet expectations. For example, supervisors have high expectation on students (i.e. personal characteristics and thinking) and similarly students expect a lot from their supervisors (i.e. in terms of personal characteristics, styles, expertise). If, however, these expectations are not met, where good working relationship and effective communication are lacking, failure in research supervision will result.

The proposed framework is expected to promote development of good fit between students and supervisors that will lead to a good working relationship. The proposed framework does not take away the responsibility of supervisors to doctoral students but augments the quality of the supervision process by providing a better understanding towards supervisory expectations and supervisory relationships. The framework also does not negate the importance of understanding the supervision triangle shown in Figure 1. However, it provides additional steps to make the supervision process more focused and explicit, and gives a flexible means of managing the relationships between the two parties. This is achieved by understanding the first challenge in the supervision process, which is the supervisory expectation of the research process. Furthermore, fulfilling the expectation stage of the framework encourages a doctoral researcher to identify the gap or the contribution of their research that can improve their research quality which will promote the effectiveness in supervision and ultimately reduce the attrition rate; a prevalent problem in managing doctoral studies [34].

Figure 2 illustrates the two-phase framework for managing expectations towards effective supervision. The first and second step constitutes the first phase in managing expectations, while the third and fourth step is the second phase. The success of second phase depends on the success in executing the steps in the first phase.

In step 1 of the first phase, students and supervisors communicate their expectations at the beginning of the supervision process. Both parties must clearly define their own expectations on the way the supervision process should progress and the milestones to be achieved for the whole journey of the research. The success of this step will determine the success of the next step, where students and supervisors formally negotiate their respective expectations. Formally negotiating expectations is an approach in developing a good relationship suggested by Hemer [10]. Upon success of the second step, each party will then perform according to their negotiated expectation and personal styles. Thus, it is critical for students and supervisors to align their expectations and styles before the supervision process begins. Once this phase is successfully negotiated; it would be smooth sailing for the remaining processes and research journey as the challenge will now be only in managing the execution of the agreed expectations.

In the second phase, the main task for the supervisor is to monitor students' progress, that is, to keep track of development of students' knowledge, skills and attitude so that knowledge, skills and attitudes thus developed are aligned with the research process requirements and the final goals. Key skills of supervisors at this phase are knowledge and skills of the related domain indicating the need for supervisors themselves to develop new knowledge and skills, and attitude to provide effective supervision. Thus, managing expectations framework is helpful in guiding the development of good supervisor-doctoral student relationship which will promote successful this completion. 


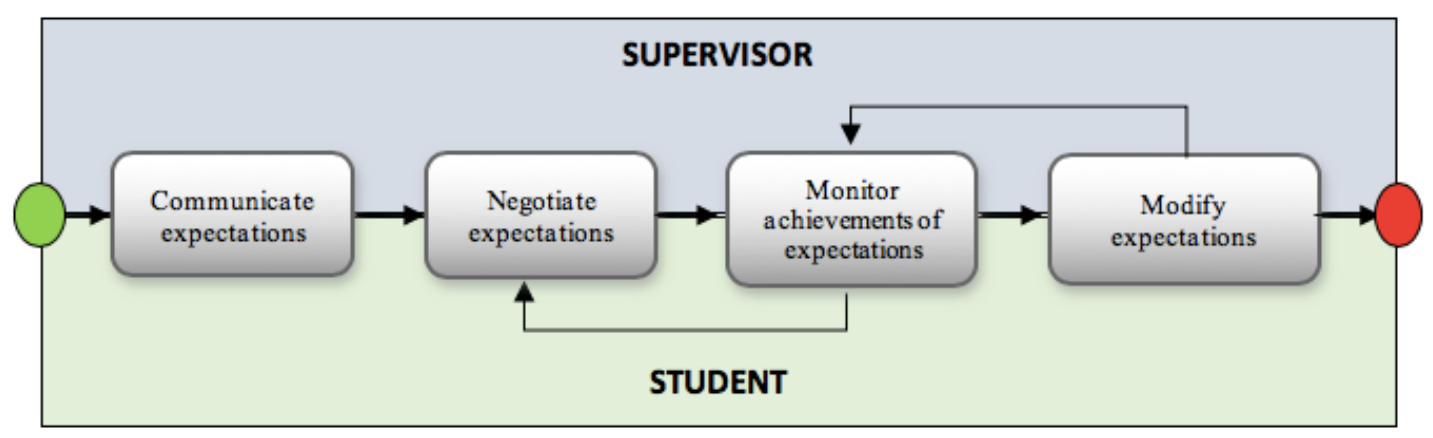

Figure 2. Framework for effective supervision

\section{Conclusions}

This study sets out to understand what effective supervision looks like in reality and to identify factors that influence supervision of doctoral students with the aim of providing a working framework that can promote effective supervision. Supervision is certainly not a straight forward process and diverse definitions of effective supervision are the norm which can influence how supervisory system functions. Key factors, namely: environment, attitude and aptitude of doctoral students, and experience and training of supervisors are identified to be important in promoting effective supervision. Specifically, however, fit between doctoral students and supervisors' expectations has been identified as the key in establishing effective supervision of doctoral research. The way these two groups of people interact (supportive or destructive) rather than either party alone is critical towards achieving effective supervisions. Thus, both parties need to equip themselves for an effective supervision to take place. A framework for promoting effective supervision via effective management of expectations has been proposed based on this understanding. It is an intuitively practical framework that focuses on establishing a strong foundation for the supervision journey. Testing this framework to generate empirical data can be the next step in validating the framework for future use.

\section{Acknowledgments}

Special thanks to Research Fund E15501, Research Management Centre, UTHM.

\section{REFERENCES}

[1] The World Bank Group. Data: Researchers in R\&D (per million people), 2015, Accessed from http://data.worldbank.org/indicator/SP.POP.SCIE.RD.P6/c ountries

[2] Grant, K., Hackney, R., \& Edgar, D. Postgraduate
Research Supervision: An 'agreed' Conceptual view of Good Practice through Derived Metaphors. International Journal of Doctoral Studies, 9, 2014, 43-60.

[3] McCallin, A. \& Nayar, S. Postgraduate research supervision: a critical review of current practice. Teaching in higher education 17, 2012, 63-74.

[4] McCormack C. Tensions between student and institutional conceptions of postgraduate research. Studies In Higher Education, 29, 2004, 319-334.

[5] Vilkinas, T. An exploratory study of the supervision of Ph.D./research students' theses. Innovative Higher Education, 32(5), 2008, 297-311. http://doi.org/10.1007/s10755-007-9057-5

[6] Gill, P., \& Burnard, P. The student-supervisor relationship in the $\mathrm{PhD} /$ Doctoral process. British Journal of Nursing, 17(10), 2008, 668-672.

[7] Orellana, M. L., Darder, A., Pérez, A., \& Salinas, J. Improving doctoral success by matching $\mathrm{PhD}$ students with supervisors. Int. Journal of Doctoral Studies, 11, 2016, 87-103.

[8] Jones, M. Issue in doctoral studies- forty years of journal discussion: Where have we been and where are we going? International Journal of Doctoral Studies, 8, 2013, 84-104.

[9] Azure, J.A. Students' perspectives of effective supervision of graduate programmes in Ghana. American $J$. of Edu. Research, 4(2), 2016, 163-169.

[10] Hemer, S.R. Informality, power and relationships in postgraduate supervision: Supervising $\mathrm{PhD}$ candidates over coffee. Higher Edu. Research \& Development, 3 (6), 2012, 827-839

[11] Ali, P.A., Watson, R. \& Dhingra, K. Postgraduate research students and their supervisors' attitude towards supervision. International Journal of Doctoral Studies, 11, 2016, 227-241.

[12] Turner, G., \& McAlpine, L. Doctoral experience as researcher preparation: activities, passion, status. International Journal for Researcher Development, 2(1), 2011, 46-60. http://doi.org/10.1108/17597511111178014

[13] Desni, C., Colet, N.R., \& Lison, C. Doctoral supervision in North America: Perception and challenges of superivosr and supervisee. Higher Education Studies, 9(1), 2019, 30-39.

[14] Richards, K.A. R. \& Fletcher, T. (2020). Learning to work 
together: conceptualizing doctoral supervision as a critical friendship. Sport, Education and Society, 25(1). doi.org/10.1080/13573322.2018.1554561

[15] Zuber-Skerritt, O., \& Fletcher, M. The quality of an action research thesis in the social sciences. Quality Assurance in Education, 15(4), 2007, 413-436. http://doi.org/10.1108/09684880710829983

[16] Lee, A. M. Developing Effective Supervisors: Concepts of Research Supervision. South African Journal of Higher Education, 21(4), 2007, 680-693.

[17] Lee, A. How are doctoral students supervised? Concepts of doctoral research supervision. Studies in Higher Education 33(3), 2008, 267-281.

[18] Ives, G., \& Rowley. G. Supervisor selection or allocation and continuity of supervision: $\mathrm{PhD}$ students' progress and outcomes. Studies in Higher Education 30(5), 2005, $535-555$.

[19] Emilsson, U. \& Johnsson. E. Supervision of supervisors: on developing supervision in postgraduate education. Higher Education and Research Development 26 (2), 2007, 163-179.

[20] Deuchar, R. Facilitator, director or critical friend? contradiction and congruence in doctoral supervision styles. Teaching in Higher Education, 13 (4). 2008, 489-500.

[21] Mainhard, T., Van der Rijst, R., Van Tartwijk, J., \& Wubbels, T. A model for the supervisor-doctoral student relationship. Higher Education, 58(3), 2009, 359-373 http://doi.org/10.1007/s10734-009-9199-8

[22] Golde, C. Adapting signature pedagogies in doctoral education: the case of teaching how to work with the literature. In The Routledge doctoral supervisor's companion: Supporting effective research in education and the social sciences, ed. M. Walker and P. Thomson, London: Routledge, 2010.

[23] Mohamed, A., Ismail, A. H., Mustaffa, M. M., \& Mohd, N. Exploring Factors Influencing the Success of Doctoral Students in Engineering. Procedia - Social and Behavioral Sciences, $\quad 60, \quad 2012, \quad 325-332$. http://doi.org/10.1016/j.sbspro.2012.09.387

[24] Wisker, G., Robinson, G., \& Shacham, M. Postgraduate research success: communities of practice involving cohorts, guardian supervisors and online communities. Innovations in Education and Teaching International, 44(3), 2007, 301-320 http://doi.org/10.1080/14703290701486720
[25] Abiddin, N., \& Ismail, A. Effective Supervisory Approach in Enhancing Postgraduate Research Studies. Int. Journal of Humanities and Social Science, 1(2), 2011, 206-217.

[26] Ismail, A., \& Hassan, R. The Basis of Supervisory Practice for Vocational Education and. Proceedings Seminar of Postgraduates Education in TVE, 2(1), 2012, 18-29.

[27] Shaw, M., \& Green, D. H. Benchmarking the PhD - a tentative beginning. Quality Assurance in Education, 10(2), 2002, $116-124$.

http://doi.org/10.1108/09684880210423609

[28] Scaffidi, A. K., \& Berman, J. E.. A positive postdoctoral experience is related to quality supervision and career mentoring, collaborations, networking and a nurturing research environment. Higher Education, 62(6), 2011, 685-698. http://doi.org/10.1007/s10734-011-9407-1

[29] Currey, J., Oldland, E., Considine, J., Glanville, D., \& Story, I. Evaluation of postgraduate critical care nursing students' attitudes to, and engagement with, Team-Based Learning: A descriptive study. Intensive and Critical Care Nursing, 31(1), 2015, 19-28. http://doi.org/10.1016/j.iccn.2014.09.003

[30] Sambrook, S., Doloriert, C., \& Stewart, J. Innovations in understanding doctoral supervision. International Conference on Human Resource Development Research and Practice across Europe, 10(1), 2009, 1-15.

[31] Bøgelund. P. How supervisors perceive $\mathrm{PhD}$ supervision And how they practice it. International Journal of Doctoral Studies, 10, 2015, 39-55. Retrieved from http://ijds.org/Vol10/IJDSv10p039-055Bogelund0714.pdf

[32] Taylor, S. E. Changes in doctoral education early career researchers. International Journal for Researcher Development, $\quad 3(2), \quad 2013 \quad 118-138$. http://doi.org/10.1108/17597511311316973

[33] Williamson, M., Laybourn, P., Deane, J., \& Tait, H. Closing the Gap: an exploration of first year students' expectations and experiences of learning. Psychology Learning and Teaching, 10(2), 2011, 1-34.

[34] Segawa, J. K., \& Rwelamila, P. D. The research skill factor as a cause for high postgraduate attrition rate. Journal of Engineering, Design and Technology, 7(3), 2009, http://doi.org/10.1108/17260530910998703

[35] Sverdlik, A., Hall, N.C., McAlpine, L, Hubbard, K. The Phd Experience: A review of the factors influencing doctoral students' completion, achievement and well-being. International Journal of Doctoral Studies, 13, 2018. 